IIUL IISER

LUXEMBOURG InSIITUTE OF

SOCIO-ECONOMIC RESEARCH

Television and the Labour Supply:

Evidence from

the Digital Television Transition in the

UK

Adrián NIETO CASTRO ${ }^{1}$ 
LISER Working Papers are intended to make research findings available and stimulate comments and discussion. They have been approved for circulation but are to be considered preliminary. They have not been edited and have not been subject to any peer review.

The views expressed in this paper are those of the author(s) and do not necessarily reflect views of LISER. Errors and omissions are the sole responsibility of the author(s). 


\title{
Television and the Labour Supply: Evidence from the Digital Television Transition in the UK
}

\author{
Adrián Nieto*
}

March 2020

\begin{abstract}
This paper exploits exogenous variation in the date of transition from analogue to digital television signal in the UK across more than 40,000 geographical units to investigate the causal impact of television on employment probabilities and potential mechanisms. Using a large individual panel survey dataset and a difference-in-differences model that compares the outcomes of adults living in regions where the switchover occurred in different years, I find that the digital transition increases employment probabilities. The impact is driven by mothers and is due to an increase in part-time and self-employment. The effect increases with the number of children in a household and when the parent does not cohabit with a partner. A possible explanation for these results is that television keeps children busy, reducing the amount of housework that parents need to do and allowing them to focus on their careers. I test whether the digital transition reduces the time that individuals dedicate to housework and show that this is the case for mothers but not for fathers and non-parents. I find no effect on time allocation other than via housework.
\end{abstract}

Keywords: labour supply, housework, leisure, gender equality, television, digital transition

JEL classification: J01, J16, J22.

${ }^{*}$ Luxembourg Institute of Socio-Economic Research (LISER), 11 Porte des Sciences, 4366 Eschsur-Alzette. E-mail: adrian.nietocas@gmail.com. I am grateful to Andrea Albanese, Sarah Bridges, Frédéric Docquier, Gianni De Fraja, Joël Machado, Miguel Ángel Malo, Javier Olivera, Fernando Rodríguez, Marc Suhrcke, Konstantinos Tatsiramos, Michel Tenikue, and Alexandros Theloudis for their feedback and valuable suggestions. I also thank participants at seminars at LISER. 


\section{Introduction}

Television viewing, one of the most important leisure activities for the majority of individuals, has been commonly associated with obesity, disease, violence, and poor mental health (Tucker and Bagwell, 1991; Johnson et al., 2002; Hu et al., 2003; Hamer et al., 2010; Grøntved and Hu, 2011; Tahir et al., 2018), as well as with a reduction in the time parents spend with children (Vandewater et al., 2006). Changes in time allocation and adverse health outcomes can have implications for labour supply, but surprisingly, the effect of TV watching on employment has been largely unexplored. The only existing evidence reports that watching television in childhood is positively correlated with the likelihood of being unemployed during adulthood (Landhuis et al., 2012). Yet, no causal evidence is provided.

The aim of this paper is to identify the causal effect of television on employment probabilities and to shed light on the underlying mechanisms. Estimating this impact is challenging as there may be confounders correlated with both the time spent watching TV and labour market status. Furthermore, the employment situation of an individual may be a determinant of the time $\mathrm{s} /$ he spends watching television. I address identification concerns by exploiting the transition from analogue to digital television signal in the United Kingdom as a natural experiment. This process took place between 2008 and 2012 and upgraded every television transmitter in the UK to interrupt the transmission of analogue signal and start the provision of high-power digital signal. As television transmitters are based in different regions and were upgraded at different times, individuals gained access to digital signal in different years depending on the region in which they lived. I obtain data on the digital transition deadlines by web-scraping the DigitalUK website, which allows me to exploit exogenous variation in the digital switchover date across more than 40,000 geographical units. The schedule of the digital transition was implemented by two independent organizations (Ofcom and DigitalUK), based on the physical features of television broadcasters that had been constructed in the 1960s and 1970s. This makes it unlikely that the digital transition is correlated with unobserved de- 
terminants of the labour market. The switchover introduced digital television to millions of households, and the number of terrestrial channels increased from 5 to 40 on the date of its implementation. ${ }^{1}$ According to UK Broadcasters' Audience Research Board (BARB) data, this increased television viewing time by $10 \% .^{2}$ Prior literature has used the digital transition in Italy to examine the causal impact of television on voting (Barone et al., 2015) and notions of crime (Mastrorocco and Minale, 2018), and the digital switchover in the UK to study the causal effect of television on education (Nieto, 2019).

I link switchover information with the first seven waves of the Understanding Society Survey, which has tracked more than 83,000 individuals in the UK on a yearly basis since 2009. After doing so, I assemble a large panel that contains yearly data on the labour and time allocation outcomes of the sampled individuals and on their digital transition deadlines. Using this information, I implement a differencein-differences model that compares the employment status of adults who received access to digital television signal in different years.

I provide several new findings. First, I show that the digital transition raises the employment probability of mothers by $2.3 \%$ but find no impact for fathers and non-parents. Second, the digital transition only increases the likelihood of mothers being part-time employees and self-employed, which are flexible types of employment. Finally, the impact becomes higher when the parent does not cohabit with a partner, increases with the number of children in a household, and is only present for parents of children aged 5-9. The previous set of estimates is subject to the digital transition being an exogenous event. I provide evidence supporting this statement by (i) showing no pre-trends in labour outcomes, (ii) performing balancing tests, (iii) controlling for region-year dummies that capture differential trends in the labour market across regions, (iv) using control groups that are unlikely to be affected by the digital transition, (v) testing for selection, (vi) adopting alternative

\footnotetext{
${ }^{1}$ The digital transition also allowed the broadcasting of TV content in multiple languages, improved definition, and increased multimedia content.

${ }^{2}$ This is reported in https://www.barb.co.uk/trendspotting/data/average-weekly-viewing/ (accessed March 31, 2019).
} 
specifications, and (vii) using different samples.

The previous findings show that the presence of children is crucial for the digital transition to have a positive impact on employment. I explore plausible mechanisms as to why this is the case and firstly test whether the digital transition reduces the number of hours that adults devote to housework. I find that this is the case for mothers but not for fathers and non-parents. I also show that the digital transition decreases the likelihood of individuals reporting that families suffer if the mother works full-time. The estimates suggest that television may keep children busy, reducing the amount of housework that parents need to do and allowing them to focus on their careers. I examine whether the switchover changes the time allocation of adults other than via housework and find that it has no effect on the amount of time individuals dedicate to (i) sleeping, (ii) visiting friends, (iii) commuting, (iv) artistic activities, (iv) social events, (v) eating with family, (vi) sports, and (vii) any other kind of leisure activity. The digital transition uniquely increases television viewing time and reduces reading, which is unlikely to explain the positive impact of the digital transition on labour supply.

This paper contributes to several literatures. First, I contribute to the literature on the relationship between children and gender equality. Previous evidence has shown that children reduce labour market participation, hours of work, managerial duties, and the employment probability of mothers relative to fathers (Angrist and Evans, 1998; Lundberg and Rose, 2000; Bridges and Mumford, 2001; Michaud and Tatsiramos, 2011; Angelov et al., 2016; Cools et al., 2017; Kleven et al., 2018), which increases the gender wage gap. Given the key role of children in gender inequality, a large number of studies have investigated the impact of child arrangements on the labour market. Some important findings are that parental leave raises employment for females (Ruhm, 1998), childcare services and subsidies improve their career opportunities (Connelly, 1992; Chevalier and Viitanen, 2002; Del Boca, 2002; Berlinski and Galiani, 2007; Boeri and Van Ours, 2013; Brewer et al., 2016), and grandparent assistance increases female labour market participation (Posadas and 
Vidal-Fernandez, 2013). I contribute to these studies by showing causal evidence on another factor that contributes towards mothers' labour supply: home-based leisure. Second, this paper relates to the literature that explores the determinants of the labour performance of individuals. Previous studies have shown that a better health condition (Bartel and Taubman, 1979; Stewart, 2001) and higher level of education (Angrist and Keueger, 1991) raise the employment probability and earnings of individuals. Besides the previous socioeconomic characteristics, the supply of public services such as public transport and sport facilities improves career prospects (Lechner, 2009; Tyndall, 2017). I contribute to this literature by examining an unexplored but relevant determinant of the labour supply: home-based leisure. Lastly, I add to the literature on the impact of television on a wide range of outcome variables. For example, several studies have investigated the impact of television on educational performance (Keith et al., 1986; Christakis et al., 2004; Hancox et al., 2005; Gentzkow and Shapiro, 2008; Nieto, 2019), political outcomes (Gentzkow, 2006; DellaVigna and Kaplan, 2007; Barone et al., 2015), living conditions of women (Jensen and Oster, 2009), fertility (La Ferrara et al., 2012), and crime concerns (Mastrorocco and Minale, 2018). I contribute to this literature by studying the causal effect of television on an unexplored outcome variable: the labour supply.

The article proceeds as follows. Section 2 describes the digital television transition in the United Kingdom. Section 3 discusses the datasets I use in the analysis. Section 4 explains the empirical model and presents the estimates on the impact of the switchover on the labour market. Section 5 explores heterogeneity in the previous effect by parental status and gender. Section 6 investigates plausible mechanisms. Section 7 concludes.

\section{The Digital Television Transition}

This paper studies the causal effect of home-based leisure on the labour supply using the digital television transition that occurred in the UK between 2008 and 2012 as a natural experiment. This technological revolution consisted in the upgrade of every 
television transmitter to interrupt the transmission of analogue signal and begin the broadcast of high-power digital signal. The digital transition introduced digital television to more than 10 million people and increased the number of television channels they could watch from 5 to 40. The switchover revolution also introduced the possibility of watching television in multiple languages, offered multimedia services, improved definition, and permitted television channels to transmit more than one TV programme at the same time.

As shown in Figure 1, the digital transition occurred in different years in the different Lower Layer Super Output Areas (LSOAs). This is because the digital transition materialized on a different date for each television transmitter group, which are located in different regions. ${ }^{3}$ LSOAs frequently receive TV signal from several different transmitter groups and so had different switchover deadlines. There are more than 40,000 LSOAs in the UK, which generates considerable geographical variation in the timing of the natural experiment.

It is important to bear in mind that the UK government assigned Ofcom and DigitalUK the task of implementing the digital transition. The former is the media administrator in the UK, and the latter is an autonomous not-for-profit institution. ${ }^{4}$ Their unique objective was to complete the digital transition according to a schedule based on the physical features of the television transmitters in the UK. These had been constructed in the 1960s and 1970s, decades before the switchover revolution started. Consequently, it is unlikely that the digital transition is correlated with unobservable determinants of the labour market.

As shown in panel A of Figure 2, the digital transition substantially increases the average television viewing time in the United Kingdom. The commencement and completion date of the transition are displayed with blue lines. Television viewing time does not change much in the years prior to the commencement of the transition

\footnotetext{
${ }^{3}$ There are 81 transmitter groups in the United Kingdom, each of which consists of one principal and several relay transmitters. Principal broadcasters generate television signal, and relay broadcasters repeat the signal so that it reaches television sets that cannot receive it from the principal broadcasters. There are 81 principal transmitters and 1,154 relay transmitters in the UK.

${ }^{4}$ Nieto (2019) gives a full description of the tasks that were assigned to Ofcom and DigitalUK, respectively.
} 
but sharply increases right after its start. TV viewing time remains higher during the transition but gradually falls after the end of the process. The latter may be due to a rise in the demand for subscription services such as Netflix and Amazon Prime Video or because of the increase in the time that people dedicate to smartphones and tablets. Panel A of Figure 2 shows that TV viewing time is $10 \%$ higher during the transition process than in the years prior to its start. ${ }^{5}$

Besides the increase in television viewing time, the digital transition reduced the audience share of the channels that could be watched through analogue signal. ${ }^{6}$ As shown in panel B of Figure 2, the proportion of television viewing time that individuals dedicate to these channels declines by $6.6 \%$ during the digital transition. This is due to a rise in the audience share of the digital channels. However, despite the previous changes, the type of television content that people watch does not vary during the digital transition. To see this, Figure 3 displays the proportion of television viewing time that individuals dedicate to each type of television content from 2007 to 2014. I define eight genres of television content: entertainment, soap operas, cultural programmes, contemporary matters, newscasts, educational contents, cartoons, and music/films. The audience shares of the different genres remain unchanged during the period of study, which suggests that the digital transition only raised television viewing time. ${ }^{7}$

\footnotetext{
${ }^{5}$ I obtain this percentage from the difference between the minutes that a representative person spends watching TV in the last years of the transition and the minutes that $\mathrm{s} /$ he spends watching TV in the years prior to the transition. I then divide this difference by the average TV watching time prior to the switchover.

${ }^{6}$ The channels BBC One, BBC Two, ITV, Channel 4, and Channel 5 were available via analogue television.

${ }^{7}$ I adopt a finer classification of genres in Appendix A.1 and also find that the transition process had no effect on the audience shares of the different genres.
} 


\section{Data}

\subsection{Digital Television Data}

The analysis uses data on the digital transition deadlines in the United Kingdom at the postcode level, which I obtain by web-scraping the DigitalUK website. The web-scraping programme first compiles data on the broadcasters that provide television signal to a particular postcode, and taking into consideration the switchover deadlines of these television transmitters, assigns to it the transition deadline of the first television broadcaster upgraded in that postcode. I extract additional data on several features of the digital transition such as the quality of the digital signal that every television transmitter provides to each postcode and whether television broadcasters are principal or relay ones. The number of postcodes in the United Kingdom is 1.7 million, and so I use accurate geographical information on the date when the digital transition occurred.

\subsection{Understanding Society Survey Data}

The paper uses the first seven waves of the Understanding Society survey (UKHLS, 2019a). This is a large longitudinal survey dataset that contains labour and timeallocation information for more than 83,000 individuals who have been followed on yearly basis since 2009. Regarding labour outcomes, the Understanding Society survey provides data on employment status (employed, self-employed, or unemployed), labour income, managerial duties, absenteeism, and hours of work. Moreover, the dataset contains information on whether individuals are white-collar, hold full-time labour contracts, and are permanent employees. Regarding time allocation, the Understanding Society survey includes data on the time that individuals dedicate to housework, television, sleeping, and commuting, among other things. It also provides information on the frequency with which individuals visit friends, take part in sports, arts, and social events, eat with family, cook, go grocery shopping, clean, wash, and get involved in childcare, among other activities. 
The Understanding Society survey contains rich sociodemographic data about individuals. For example, it provides data on their gender, age, sexual orientation, ethnicity, nationality, level of education, parental, marital, and religious status. Moreover, it contains data on household characteristics such as household income, size, number of children, bedrooms, and cars. Finally, the Understanding Society survey provides data on the LSOA of residence of individuals, which I access after receiving permission from the UK Data Service (UKHLS, 2019b). There are 42,621 LSOAs in the UK, and their average population is $1,500 .{ }^{8}$ I merge this information with a dataset provided by the UK's Office for National Statistics of the existing postcodes within every LSOA in the UK. I then link the combined dataset with the information on the digital transition deadlines at the postcode level in the UK. As the LSOA is the smallest geographical level that I can observe in the Understanding Society survey, the analysis exploits variation in the switchover deadlines at this level. I can identify individuals across the different waves of the Understanding Society survey, and so I assemble a large panel that provides yearly labour and time allocation information at the individual level. I restrict the sample to individuals who are present in the dataset before and after their respective digital transition deadlines. After implementing this restriction, I obtain an unbalanced panel of more than 180,000 observations, which follows approximately 40,000 individuals on a yearly basis from 2009 to 2014 .

\subsubsection{Summary Statistics}

This section presents summary statistics of several sociodemographic and labour characteristics of the sample. Column 1 of Table 1 provides unweighted descriptive statistics regarding the gender, nationality, age, civil status, and size of the household where individuals live. It also presents unweighted summary statistics of some

\footnotetext{
${ }^{8}$ There are no LSOAs in Scotland and Northern Ireland. Instead, the names of the most precise areas that are available in the dataset for these two countries are Data Zones and Super Output Areas, respectively. There are 6,505 Data Zones in Scotland, and their populations range from 500 to 1,000 people. There are 890 Super Output Areas in Northern Ireland, and their populations are between 1,300 and 2,800. The analysis uses these geographical units instead of LSOAs for Scotland and Northern Ireland, respectively.
} 
labour characteristics such as the type of contract, level of qualification, probability of having a job, likelihood of being unemployed and active in the labour market. Columns 2-5 of Table 1 split the sample depending on the year in which individuals obtained access to digital television. This allows me to explore whether the switchover is unconditionally correlated with observable characteristics. As shown in Table 1, people living in areas where the digital transition occurred earlier are more likely to be native, single, separated, widowed, older, and live in households with fewer members. The digital switchover does not seem to be unconditionally correlated with the type of contract, employment and labour participation probabilities, or other sociodemographic characteristics. Later in the paper, I provide evidence on the digital transition being conditionally uncorrelated with every sociodemographic and labour characteristic once I account for LSOA and year fixed effects.

\section{Methodology and Baseline Results}

\subsection{Empirical Model}

This section describes the difference-in-differences model that I estimate to study the causal impact of television on employment probabilities. I use the digital television transition that occurred in the United Kingdom between 2008 and 2012 as a natural experiment and take advantage of exogenous variation in the year when it was implemented across 42,621 LSOAs in the UK. I estimate the following model:

$$
y_{i, t}=\alpha+\beta D T_{j, t}+\theta X_{i, t}+\eta_{j}+\lambda_{t}+\varepsilon_{i, t}
$$

where $y_{i, t}$ is a dummy that takes a value of 1 if individual $i$ has a job at year $t$ and 0 otherwise. $D T_{j, t}$ is a dummy that takes a value of 1 if the digital transition has taken place by year $t$ in the LSOA where individual $i$ lives and 0 if it has not yet occurred. I denote LSOAs with subindex $j$. Given the large number of LSOAs, 
I exploit accurate geographical variation in the schedule of the digital transition. $X_{i, t}$ is a vector of individual characteristics that includes gender, a third-order polynomial in age, ethnicity, level of qualification, marital status, and the number of household members. $\eta_{j}$ are LSOA fixed effects controlling for time-invariant unobserved characteristics at the LSOA level. $\lambda_{t}$ is a set of year dummies that account for the yearly variation in the outcome variable common across individuals. Finally, $\varepsilon_{i, t}$ is the error of the specification and varies at the individual level and over time. Standard errors are clustered within LSOAs.

$\beta$ is the effect of the digital transition on employment probabilities. The validity of the empirical approach relies on the digital transition being uncorrelated with unobserved determinants of the labour supply once I control for observable covariates, LSOA indicators, and year dummies. This is likely to be the case because the digital transition is implemented by Ofcom and DigitalUK, which are two independent organizations. The task of these institutions was to complete the digital transition following a specific schedule based on the physical attributes of the television transmitters in the UK, which had been constructed in the 1960s and 1970s. Section 4.3 provides evidence supporting the empirical strategy and showing that the exogeneity claim is likely to be satisfied.

\subsection{Baseline Results}

This section presents evidence of the causal effect of the digital transition on employment probabilities. To do so, column 1 of Table 2 presents the unconditional estimate of the impact of the digital switchover, column 2 displays the estimate of the digital transition after I control for LSOA and year fixed effects, and column 3 shows the estimates of the baseline specification, which also controls for observable covariates at the individual level. As shown in Table 2, the digital transition raises employment probabilities, and the estimates are highly significant. Regarding the magnitude of the impact, my preferred estimate indicates that the switchover process increases the employment probability by $0.6 \%$. Later in the paper, I will 
explore potential mechanisms as to why the digital transition has a positive impact on employment, and in particular, whether the previous effect may be due to a change in the time allocation of individuals. Before doing so, it is important to provide evidence supporting the empirical strategy and to explore heterogeneity in the baseline estimates to further understand the possible drivers behind the previous results.

\subsection{Robustness}

\subsubsection{Balancing Tests}

This section performs a number of balancing tests that examine whether the digital transition is correlated with pre-determined characteristics of individuals. In particular, panel A of Figure 4 shows the unconditional estimates of the digital transition on a number of pre-determined observable characteristics such as gender, age, race, nationality, sexual orientation, level of qualification, and whether individuals are religious. I also estimate whether the digital transition has an impact on the probability of individuals living in an urban area, having siblings, and on the race, nationality, and level of qualification of their parents. Panel B estimates the same balancing tests but controlling for LSOA and year dummies. The estimates indicate that the digital transition is unconditionally correlated with multiple predetermined characteristics. However, once I control for LSOA and year dummies, every estimate turns out negligible and not statistically significant, except the one for age. The latter finding is not surprising because the availability of digital television signal increases as individuals age. However, this is not a concern as I control for a third-order polynomial in age throughout the analysis.

\subsubsection{Effect over Time and Pre-trends}

This section examines the evolution of the impact of the digital transition on em-

ployment probabilities and whether there are pre-trends in the labour outcomes of individuals previous to the transition deadline. To do so, I estimate a specification 
where I control for a set of indicators for the number of years that are remaining or have passed at year $t$ relative to the transition deadline in LSOA $j$. In particular, I test for pre-trends by including three dummies equal to 1 when at year $t$ there are $0-$ 12, 13-24, and 25-36 months left for the transition to occur in LSOA $j$, respectively. I also include an indicator that equals 1 when there are 36 or more months left until the transition date of LSOA $j$. To study the evolution of the effect of television on employment probabilities, I control for three dummies that equal 1 when at year $t$, 1-12, 13-24, and 25-36 months have passed since the transition deadline in LSOA $j$, respectively. I also include a dummy equal to 1 when the number of months that have passed since the transition deadline is 36 or higher. In the specification, I control for LSOA and year fixed effects. However, there is still sufficient variation in the aforementioned set of dummies because the transition deadlines vary across LSOAs. I also control for LSOA trends to examine whether there is still variation in employment probabilities around the switchover date once I account for local trends in the labour market.

Figure 5 shows that the labour outcomes of individuals remain invariant in the years preceding the transition date. The estimates are small and not statistically significant. Figure 5 also shows that the employment probabilities of individuals increase in the years after the transition deadline. The estimates are highly statistically significant, and the impact of television on the labour market is persistent over time.

\subsubsection{Local Labour Markets}

Another possible concern is that the digital transition may be correlated with the implementation of policies or changing factors at the regional level that have an impact on the labour market. As previously argued, this is unlikely because the digital transition is implemented by two independent organizations according to the physical characteristics of television transmitters that had been built decades before the start of the switchover. Yet, this subsection further addresses this concern by esti- 
mating specifications that study the impact of the digital transition on employment probabilities once I control for year dummies, LSOA fixed effects, and region-year dummies. These models allow controlling for differential non-linear trends in the local labour markets. More specifically, columns 1-3 of Table 3 present the estimates of a specification that controls for year dummies, LSOA fixed effects, and the following region-year dummies: (i) country-year dummies, (ii) government office region-year dummies, and (iii) local authority-year dummies, respectively. There are 4 countries, 12 government office regions, and 408 local authorities in the UK. As shown in Table 3, the estimates of the digital transition are robust to the inclusion of region-year dummies.

\subsubsection{Further Sensitivity Checks}

I next estimate multiple robustness tests that support the validity of the empirical strategy and examine whether the estimates are sensitive to the adoption of alternative models. First, a potential threat to the analysis is that a part of the population may move from areas where there is no access to digital signal to areas where there is. If these individuals differ from the rest of the population in unobservable characteristics that determine labour outcomes, the baseline estimates will be biased. Column 1 of Table 4 explores this possibility by estimating the baseline model on the subsample of people who always lived in the same region. The estimate of the digital transition is analogous in magnitude to the baseline estimate and significant at the $1 \%$ confidence level. This suggests that the baseline results are not driven by individuals moving across regions. Column 2 estimates the baseline specification on the sample of individuals who do not have a TV. This test is important because the digital transition should have no impact on the employment probability of people who cannot watch TV. As shown, the estimate of the transition reform is not statistically significant for this subgroup of the population. Column 3 presents the estimates of a specification similar to the baseline one but that also controls for transmitter fixed effects. This addresses the concern of individuals receiving 
television signal from different transmitters being different in unobservable characteristics that determine their labour outcomes. Column 4 presents the estimates of the baseline model using the period of 2009-2013, which allows me to focus on the years when the digital transition occurred. As shown in columns 3-4, the estimates are robust to the use of different models and sample periods.

\section{Heterogeneity}

\subsection{The Importance of Parental Status and Gender}

The previous analysis shows that the digital transition increases the probability of having a job. I next explore heterogeneity in the previous effect to understand possible drivers of the baseline results. Previous research has shown that television changes the time-use of children (Nieto, 2019), and so it is relevant to study whether the estimates differ by parental status. To do so, I estimate a model analogous to the baseline one, except that I control for a binary variable equal to 1 when adult $i$ lives with a child younger than 16 years old and 0 otherwise, and for an interaction term between this indicator and the digital transition dummy. Panel A of Figure 6 presents the average marginal effects of the digital transition by parental status.

I find that the digital switchover markedly raises the likelihood of parents having a job and that the estimate is statistically significant at the $1 \%$ confidence level. However, the digital transition has a small and not statistically significant impact on the employment probability of non-parents. The results indicate that the impact of television on the labour market is driven by parents and therefore, that the presence of children plays a crucial role in the estimates obtained.

Previous research has shown that children reduce working hours and increase housework for mothers relative to fathers (Sanchez and Thomson, 1997). Therefore, it is important to investigate whether the impact of the digital transition on the labour market differs not only by parental status but also by gender. To do so, panel B of Figure 6 reports the estimates of the specification I estimated in panel 
A separately by gender. As shown, the digital transition increases the employment probability of mothers by $2.2 \%$, and the estimate is statistically significant at the $1 \%$ level. The estimates for fathers and non-parents are small and not statistically significant, which indicates that the impact of television on the labour market is driven by mothers. A possible explanation is that television keeps children busy, reducing the amount of housework that mothers need to do and allowing them to focus on their career. I test for this hypothesis and alternative mechanisms later in the paper.

\subsection{Composition of the Household and Gender Equality}

I next study whether the impact of the digital transition on employment probabilities is heterogeneous in cohabitation status or the number and age of children. To do so, I first re-estimate the specification I used in panel A of Figure 6 but separately for the subsample of individuals who live with a partner/spouse and for those who do not. As shown in panel A of Figure 7, the greatest impact of the digital transition on the probability of having a job is for parents who do not cohabit with a partner, and the estimate is significant at the $1 \%$ level. The estimate for parents who cohabit with a partner is also positive and significant at the $1 \%$ level, albeit it is smaller in size. Finally, the estimates are small and not statistically significant for non-parents independently of their cohabitation status. Second, I estimate a specification similar to the baseline one but that controls for the number of children younger than 16 years old living in the household of adult $i$ and for an interaction term between the aforementioned variable and the digital transition indicator. Panel B of Figure 7 displays the estimates of the switchover process and shows that the magnitude of the impact of television on the probability of having a job increases with the number of children in a household. The estimates are positive and highly significant for parents of two or more children. Third, I estimate a model analogous to the baseline one but that controls for three dummies equal to 1 when a child between $0-4,5-9$, and 10-15 years old lives in adult $i$ 's household at year $t$ and 0 
otherwise, respectively. In this model, I also control for three interaction terms between the aforementioned dummies and the digital transition indicator, respectively. As shown in panel $\mathrm{C}$ of Figure 7, the baseline estimates are driven by parents who have children between 5 and 9 years of age.

Finally, I explore heterogeneity in the baseline estimates only by gender to quantify the effect of television on gender equality in the labour market. To do so, I estimate a model similar to the baseline one but that controls for an interaction term between the digital transition indicator and a binary variable equal to 1 for females and 0 for males. Panel $\mathrm{D}$ of Figure 7 displays the average marginal effects of the digital transition by gender. The switchover increases the probability of females having a job, and the estimate is significant at the $1 \%$ confidence level. However, the estimate of the impact of the digital transition is smaller and not statistically significant for males. Albeit the estimates are not statistically different, the magnitudes suggest that the digital transition may reduce gender inequality in the labour market. Regarding the size of this reduction, the digital transition increases the employment probability of females by $0.82 \%$ but only by $0.34 \%$ for males. According to OECD data, the average employment probability of females is $53.9 \%$ in the year prior to the start of the switchover, whereas it is $66.7 \%$ for males. ${ }^{9}$ Therefore, the introduction of digital television in the UK may have decreased the gender gap in the employment probability by $3.75 \% .^{10}$

\subsection{Type of Employment}

The previous analysis has shown that the digital transition increases the employment probabilities of mothers. This section provides evidence of the effect of the digital switchover on different types of employment. To do so, I re-estimate the specification I adopted in panel B of Figure 6 but using the following outcome variables: (i) a

\footnotetext{
${ }^{9}$ This is reported in https://stats.oecd.org/index.aspx?queryid=54741 (accessed April 15,2019 ).

${ }^{10}$ Appendices A.2-A.3 further explore whether the impact of television on employment probabilities is heterogeneous in terms of the amount of public services provided in the local area and the level of qualification of individuals, respectively.
} 
dummy equal to 1 if individual $i$ is self-employed at year $t$ and 0 otherwise, (ii) an indicator for whether the individual is an employee, (iii) a dummy that takes a value of 1 if individual $i$ is a part-time employee at year $t$ and 0 otherwise, and (iv) an indicator for whether individual $i$ is a full-time employee, respectively. ${ }^{11}$ Panels A-D of Figure 8 present the estimates of the effect of the digital switchover on the previous labour outcomes, respectively. I show that the digital transition increases the probability of mothers being self-employed and employed part-time and that the estimates are highly significant. I also find that the digital transition increases the likelihood of male non-parents being self-employed, at the cost of decreasing their chances of holding full-time contracts. The rest of the estimates are not statistically significant. Overall, these results indicate that the positive impact of the digital transition on the employment probability of mothers is driven by an increase in their likelihood of being self-employed and holding part-time contracts.

\section{Mechanisms}

This paper has shown that the digital television transition in the UK only had a positive impact on the employment probabilities of mothers, which indicates that the presence of children plays a crucial role in the effect of television on the labour market. A possible explanation is that television keeps children busy, reducing the amount of housework that mothers need to do and allowing them to focus on their career. This section examines this hypothesis as a plausible mechanism behind the baseline estimates by testing whether the digital transition changes the amount of housework that individuals do. As in the previous analysis, I explore heterogeneity by parental status and gender.

I estimate a specification similar to the baseline model but that controls for parental status and its interaction with the digital transition indicator. I adopt as

\footnotetext{
${ }^{11}$ Appendices A.4-A.5 further examine whether the digital transition has an impact on working hours and the probability of working from home, respectively. Appendices A.4-A.5 also examine whether these effects are heterogeneous in parental status and gender.
} 
dependent variable the weekly number of hours that individuals dedicate to housework. As shown in panel A of Figure 9, the digital transition decreases the amount of housework that parents do, and the estimate is significant at the $1 \%$ confidence level. In contrast, the digital switchover has no impact on the amount of housework for non-parents.

As children increase the amount of housework for mothers relative to fathers (Sanchez and Thomson, 1997), it is important to explore whether the impact of the digital transition on housework also differs by gender. To do so, panel B of Figure 9 presents the estimates of the specification I estimated in panel A but separately for men and women. As shown, the digital transition reduces the number of hours that mothers dedicate to housework by 0.74 , and the estimate is statistically significant at the $1 \%$ level. However, I do not find statistically significant estimates of the digital transition for fathers and non-parents. Regarding the magnitude of the effect, mothers and fathers dedicate, on average, 16.8 and 6.4 hours per week to housework, respectively. Therefore, taking into account the estimates I have obtained, the digital transition decreases the gender difference in the time dedicated to housework by $8.3 \%$ for parents. Overall, the results indicate that the positive impact of television on the employment probabilities of mothers is likely to be due to television decreasing the amount of housework that they need to do.

Columns 1-2 of Table 5 provide further evidence of television reducing the attention that parents need to provide to children. To do so, I estimate the baseline model adopting as dependent variable the opinion of interviewees about the following statements: (i) "Children may undergo difficulties when mothers work" and (ii) "Families undergo difficulties when females work full-time", respectively. The opinions are measured on a scale that ranges from 1 to 5 , with a higher value indicating a stronger agreement with the statement. As shown, the digital transition reduces the belief that families undergo difficulties when mothers work full-time. The estimate is statistically significant at the $5 \%$ level.

Taken together, this section has investigated a plausible mechanism as to why 
the digital transition has a positive impact on the employment probabilities of mothers. I have shown that the digital switchover decreases the hours of housework for mothers, but not for fathers and non-parents. The digital transition also diminishes the suffering of families when mothers work full-time. All of these findings point towards an important conclusion: television may keep children busy, reducing housework for mothers and helping them focus on their career.

Another plausible explanation for the positive impact of television on the employment probabilities of mothers is that the new digital television content may have changed individuals' perceptions about the role of women in the labour market. This is unlikely because television content did not change much during the digital transition. Nevertheless, columns 3-4 of Table 5 test for this hypothesis. I estimate the baseline model using as dependent variable the opinions of individuals about the following statements: (i) "husbands and wives must earn money", and (ii) "the role of husbands is to earn income, the one of wives is to take care of the household", respectively. These outcome variables take a value between 1 (strongly disagrees with the statement) and 5 (strongly agrees). As shown, the digital transition does not change the opinions of individuals regarding gender equality.

The positive impact of television on employment probabilities may also be driven by television changing the time allocation of adults for activities other than housework. Columns 1-8 of Table 6 test for this hypothesis by estimating the baseline specification and using as dependent variable the number of hours that adults spend (i) watching TV, (ii) sleeping, and (iii) commuting per day and the frequency with which individuals (iv) do sports, (v) take part in arts, (vi) attend arts events, (vii) go for a walk, (viii) eat with family, (ix) visit friends, (x) read, and (xi) get involved in any other kind of leisure activity, respectively. ${ }^{12}$ As shown in Table 6, the digital transition only increases the number of hours of television viewing and

\footnotetext{
${ }^{12}$ Some of these frequencies are measured on different scales. For example, the frequency of sports ranges from 1 (do not do any sport) to 7 (3 or more times per week). In contrast, the frequency of taking part in arts or attending arts events ranges from 1 (once in the past year) to 5 (at least once per week). See www. understandingsociety.ac.uk/documentation/mainstage/dataset-documentation (accessed February 1, 2019) for more information.
} 
reduces reading frequency. The latter finding is unlikely to explain the positive impact of the digital transition on employment probabilities.

\section{Conclusions}

This paper exploits exogenous variation in the date when the digital television transition occurred in the UK across more than 40,000 geographical units to study the causal impact of television on employment probabilities and to investigate potential mechanisms. The digital transition process transformed, in stages, every television transmitter in the UK, ceasing the broadcast of analogue television signal and starting the provision of high-power digital signal, which increased the number of TV channels available from 5 to 40. Using a large panel survey dataset at the individual level and a difference-in-differences model that compares the outcomes of adults who received access to digital signal in different years, I show that the digital transition increases the employment probability of mothers but find no impact for fathers and non-parents. I also show that this effect is driven by parents of children aged 5-9 and that the estimates increase with the number of children in a household and when the parent does not cohabit with a partner. The previous estimates are subject to the digital switchover being an exogenous event. I provide evidence supporting the exogeneity claim by (i) testing for pre-trends, (ii) estimating balancing tests, (iii) controlling for region-year dummies, (iv) using control groups unlikely to be affected by the switchover, (v) testing for selection, (vi) adopting alternative specifications, and (vii) using different samples. The estimates are robust to these tests.

Having shown that the presence of children is crucial for the digital transition increasing employment probabilities, I examine potential mechanisms. I show that the digital transition reduces the amount of housework that mothers do but find no effect for fathers and non-parents. I also show that the digital transition decreases the suffering of families when mothers work full-time. These findings suggest that television may keep children busy, reducing the amount of housework that mothers need to do and helping them focus on their career. I test for alternative mechanisms 
such as whether the digital transition changes time allocation other than via housework or shapes opinions about gender equality. I find no evidence of this being the case. 


\section{References}

Angelov, N., P. Johansson, and E. Lindahl (2016). Parenthood and the gender gap in pay. Journal of Labor Economics 34(3), 545-579.

Angrist, J. D. and W. N. Evans (1998). Children and their parents' labor supply: Evidence from exogenous variation in family size. The American Economic Review 88(3), 450-477.

Angrist, J. D. and A. B. Keueger (1991). Does compulsory school attendance affect schooling and earnings? The Quarterly Journal of Economics 106(4), 979-1014.

Barone, G., F. D'Acunto, and G. Narciso (2015). Telecracy: Testing for channels of persuasion. American Economic Journal: Economic Policy 7(2), 30-60.

Bartel, A. and P. Taubman (1979). Health and labor market success: The role of various diseases. The Review of Economics and Statistics, 1-8.

Berlinski, S. and S. Galiani (2007). The effect of a large expansion of pre-primary school facilities on preschool attendance and maternal employment. Labour Economics $14(3), 665-680$.

Boeri, T. and J. Van Ours (2013). The economics of imperfect labor markets. Princeton University Press.

Brewer, M., S. Cattan, C. Crawford, B. Rabe, et al. (2016). Does more free childcare help parents work more? Technical report, Institute for Fiscal Studies.

Bridges, S. and K. Mumford (2001). Absenteeism in the uk: a comparison across genders. The Manchester School 69(3), 276-284.

Chevalier, A. and T. K. Viitanen (2002). The causality between female labour force participation and the availability of childcare. Applied Economics Letters 9(14), 915-918. 
Christakis, D. A., F. J. Zimmerman, D. L. DiGiuseppe, and C. A. McCarty (2004). Early television exposure and subsequent attentional problems in children. Pediatrics 113(4), 708-713.

Connelly, R. (1992). The effect of child care costs on married women's labor force participation. The Review of Economics and Statistics, 83-90.

Cools, S., S. Markussen, and M. Strøm (2017). Children and careers: How family size affects parents' labor market outcomes in the long run. Demography 54(5), $1773-1793$.

Del Boca, D. (2002). The effect of child care and part time opportunities on participation and fertility decisions in italy. Journal of Population Economics 15(3), 549-573.

DellaVigna, S. and E. Kaplan (2007). The fox news effect: Media bias and voting. The Quarterly Journal of Economics 122(3), 1187-1234.

Gentzkow, M. (2006). Television and voter turnout. The Quarterly Journal of Economics 121(3), 931-972.

Gentzkow, M. and J. M. Shapiro (2008). Preschool television viewing and adolescent test scores: Historical evidence from the coleman study. The Quarterly Journal of Economics 123(1), 279-323.

Grøntved, A. and F. B. Hu (2011, 06). Television Viewing and Risk of Type 2 Diabetes, Cardiovascular Disease, and All-Cause Mortality: A Meta-analysis. JAMA 305(23), 2448-2455.

Hamer, M., E. Stamatakis, and G. D. Mishra (2010). Television-and screenbased activity and mental well-being in adults. American Journal of Preventive Medicine 38(4), 375-380. 
Hancox, R. J., B. J. Milne, and R. Poulton (2005). Association of television viewing during childhood with poor educational achievement. Archives of Pediatrics 8 Adolescent Medicine 159(7), 614-618.

Hu, F. B., T. Y. Li, G. A. Colditz, W. C. Willett, and J. E. Manson (2003). Television watching and other sedentary behaviors in relation to risk of obesity and type 2 diabetes mellitus in women. JAMA 289(14), 1785-1791.

Jensen, R. and E. Oster (2009). The power of TV: Cable television and women's status in India. The Quarterly Journal of Economics 124(3), 1057-1094.

Johnson, J. G., P. Cohen, E. M. Smailes, S. Kasen, and J. S. Brook (2002). Television viewing and aggressive behavior during adolescence and adulthood. Science 295(5564), 2468-2471.

Keith, T. Z., T. M. Reimers, P. G. Fehrmann, S. M. Pottebaum, and L. W. Aubey (1986). Parental involvement, homework, and tv time: Direct and indirect effects on high school achievement. Journal of Educational Psychology 78(5), 373.

Kleven, H., C. Landais, and J. E. Søgaard (2018). Children and gender inequality: Evidence from Denmark. Technical report, National Bureau of Economic Research.

La Ferrara, E., A. Chong, and S. Duryea (2012). Soap operas and fertility: Evidence from brazil. American Economic Journal: Applied Economics 4(4), 1-31.

Landhuis, C. E., D. K. Perry, and R. J. Hancox (2012). Association between childhood and adolescent television viewing and unemployment in adulthood. Preventive Medicine 54(2), 168-173.

Lechner, M. (2009). Long-run labour market and health effects of individual sports activities. Journal of Health Economics 28(4), 839-854.

Lundberg, S. and E. Rose (2000). Parenthood and the earnings of married men and women. Labour Economics 7(6), 689-710. 
Mastrorocco, N. and L. Minale (2018). News media and crime perceptions: Evidence from a natural experiment. Journal of Public Economics 165, 230 - 255.

Michaud, P.-C. and K. Tatsiramos (2011). Fertility and female employment dynamics in Europe: the effect of using alternative econometric modeling assumptions. Journal of Applied Econometrics 26(4), 641-668.

Nieto, A. (2019). Television, time use and academic achievement: Evidence from a natural experiment. Granger Centre Discussion Paper 19/06.

Posadas, J. and M. Vidal-Fernandez (2013). Grandparents' childcare and female labor force participation. IZA Journal of Labor Policy 2(1), 14.

Ruhm, C. J. (1998). The economic consequences of parental leave mandates: Lessons from europe. The Quarterly Journal of Economics 113(1), 285-317.

Sanchez, L. and E. Thomson (1997). Becoming mothers and fathers: Parenthood, gender, and the division of labor. Gender and Society 11(6), 747-772.

Stewart, J. M. (2001). The impact of health status on the duration of unemployment spells and the implications for studies of the impact of unemployment on health status. Journal of Health Economics 20(5), 781-796.

Tahir, M. J., W. Willett, and M. R. Forman $(2018,10)$. The Association of Television Viewing in Childhood With Overweight and Obesity Throughout the Life Course. American Journal of Epidemiology 188(2), 282-293.

Tucker, L. A. and M. Bagwell (1991). Television viewing and obesity in adult females. American Journal of Public Health 81(7), 908-911.

Tyndall, J. (2017). Waiting for the r train: Public transportation and employment. Urban Studies 54(2), 520-537.

UKHLS (2019a). University of Essex, Institute for Social and Economic Research. (2019). Understanding Society: Waves 1-9, 2009-2018 and Harmonised BHPS: 
Waves 1-18, 1991-2009. [data collection]. 12th Edition. UK Data Service. SN: 6614, http://doi.org/10.5255/UKDA-SN-6614-13.

UKHLS (2019b). University of Essex, Institute for Social and Economic Research (2019). Understanding Society: Waves 1-9, 2009-2018: Special Licence Access, Census 2011 Lower Layer Super Output Areas. [data collection]. 9th Edition. UK Data Service. SN: 7248, http://doi.org/10.5255/UKDA-SN-7248-9.

Vandewater, E. A., D. S. Bickham, and J. H. Lee (2006). Time well spent? relating television use to children's free-time activities. Pediatrics 117(2), e181-e191. 


\section{Figures}

Figure 1: The Digital Television Transition in the UK
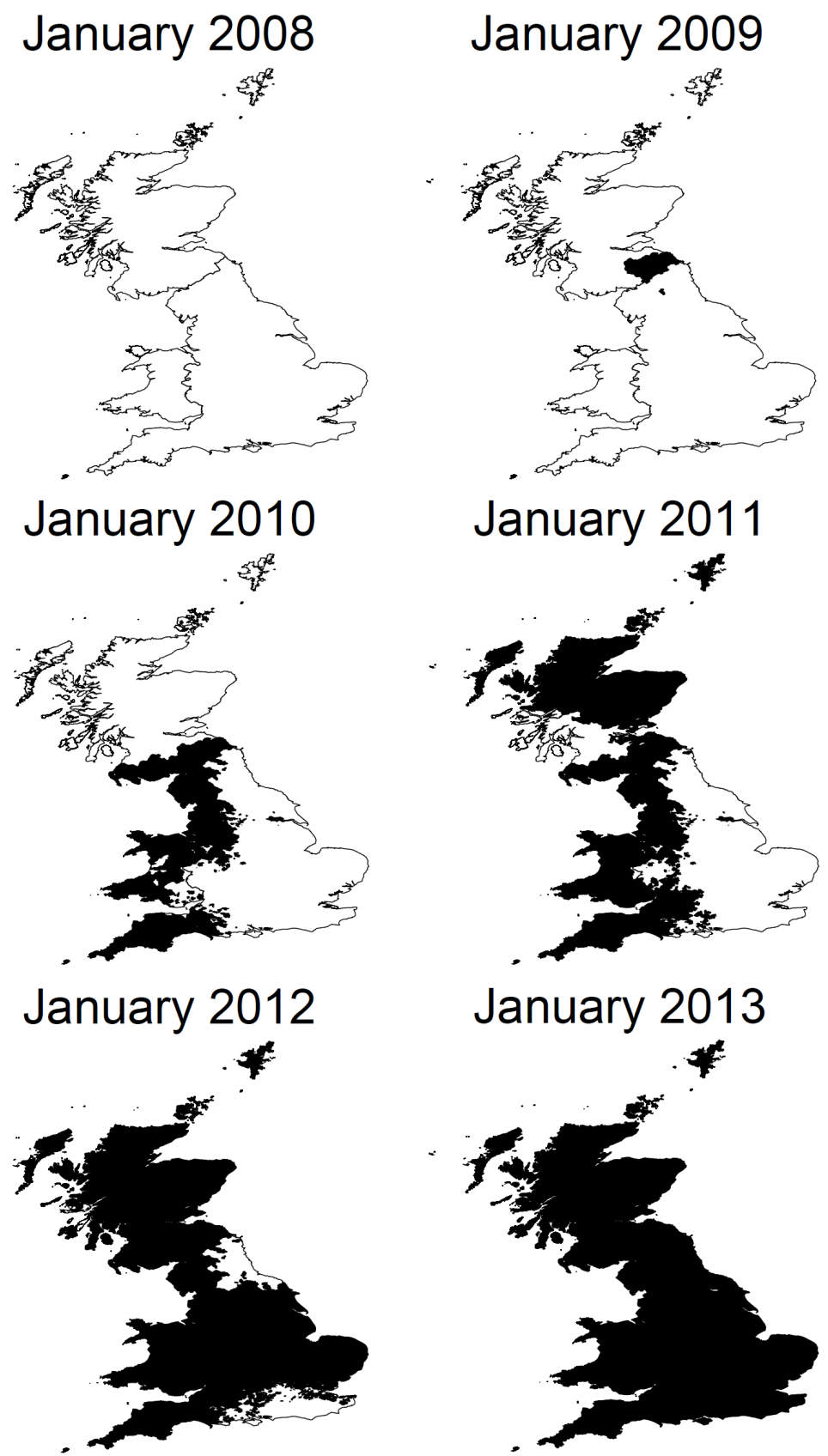

The figure shows the implementation of the digital television transition in the UK over the period of 2008-2013. The digital transition occurred in different years in the different LSOAs. Albeit not shown in the map, the analysis also includes individuals who live in Northern Ireland, where the switchover also took place between 2008 and 2012. 
Figure 2: TV Watching Time and Audience Share of Traditional Channels
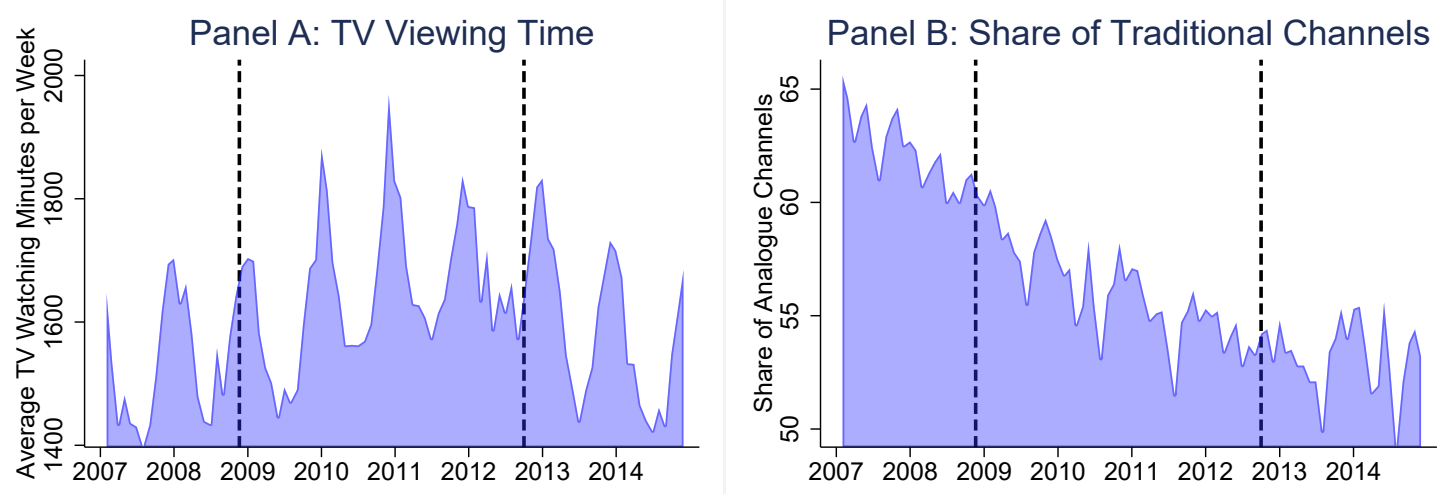

Panel A shows the average television viewing time in the UK during the period of analysis. I measure TV viewing time in minutes per week. Panel B shows the audience share of the television channels that were available through analogue signal during the period of analysis.

Figure 3: TV Viewing Share by Genre

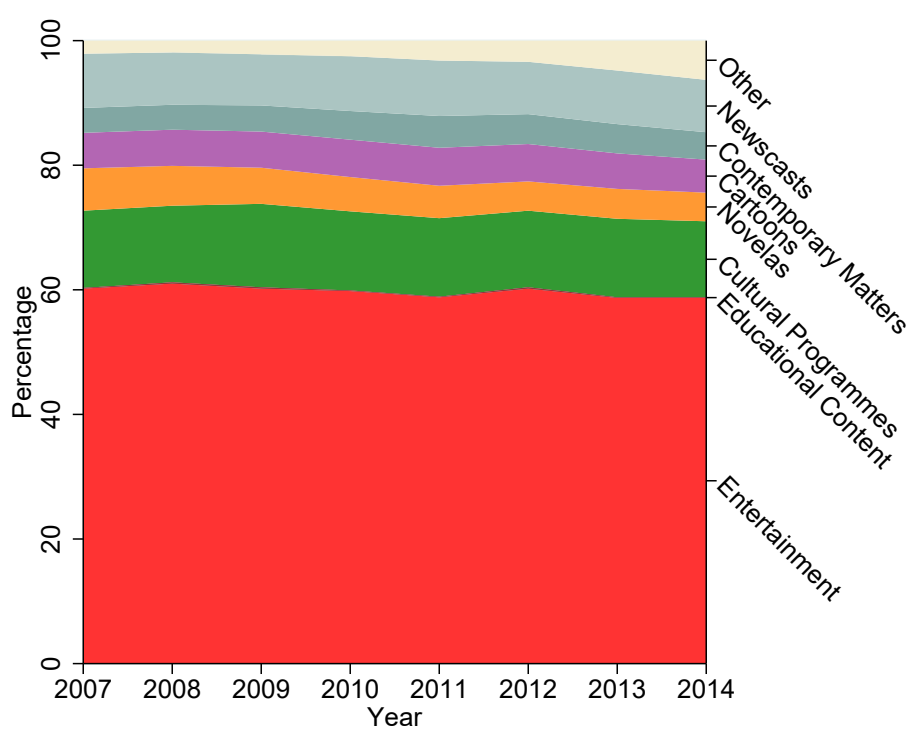

The figure shows the proportion of television watching time that viewers dedicated to each genre during the period of study. I classify genres as follows: entertainment, soap operas, cultural programmes, contemporary matters, newscasts, educational content, cartoons, and music/films. 
Figure 4: Balancing Tests
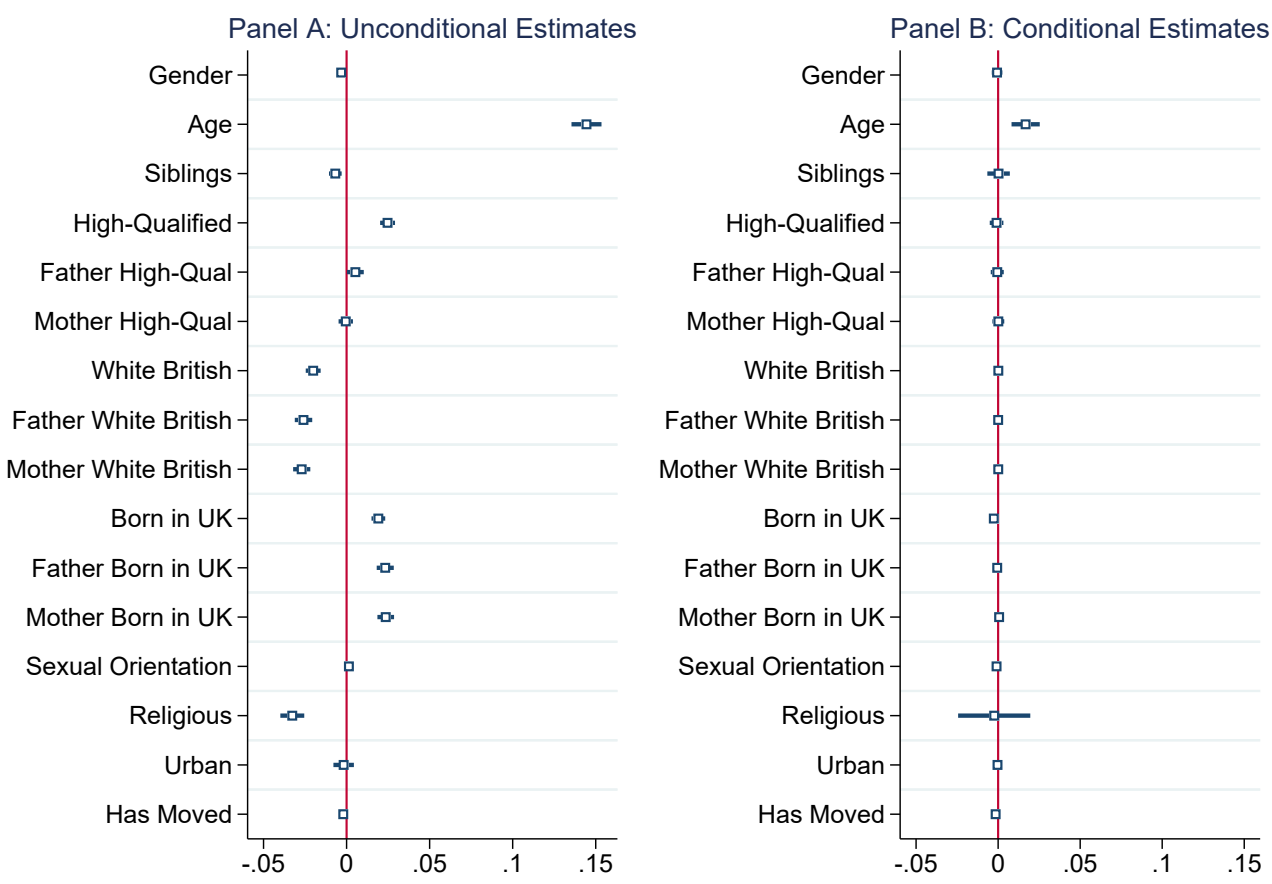

The figure shows the estimates of the impact of the digital transition on a set of predetermined characteristics. Panel A presents the unconditional estimates. Panel B displays the conditional estimates once I account for LSOA and year fixed effects.

\section{Figure 5: Evolution of the Effect of the Digital Transition}

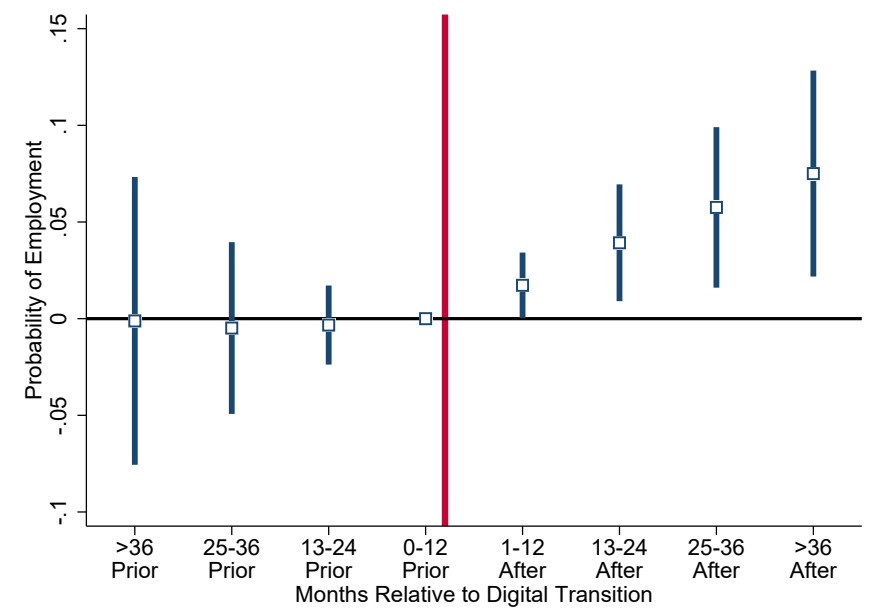

The figure shows the evolution of the impact of the transition from analogue to digital television on the probability of employment. 
Figure 6: Parental Status and Gender
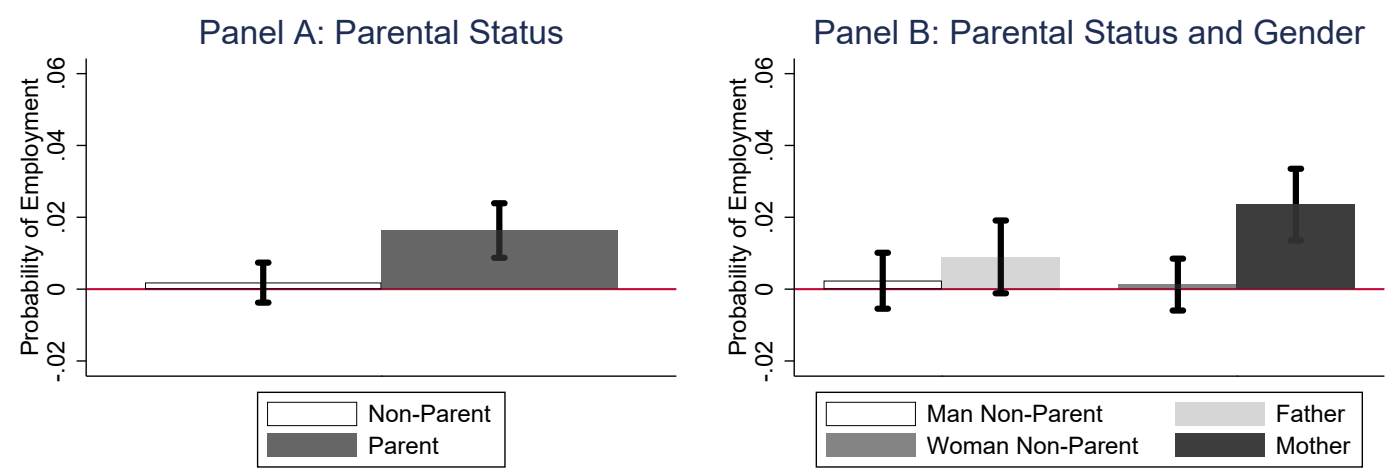

The figure examines whether the impact of television on the employment probability is heterogeneous in parental status and gender.

Figure 7: Heterogeneity
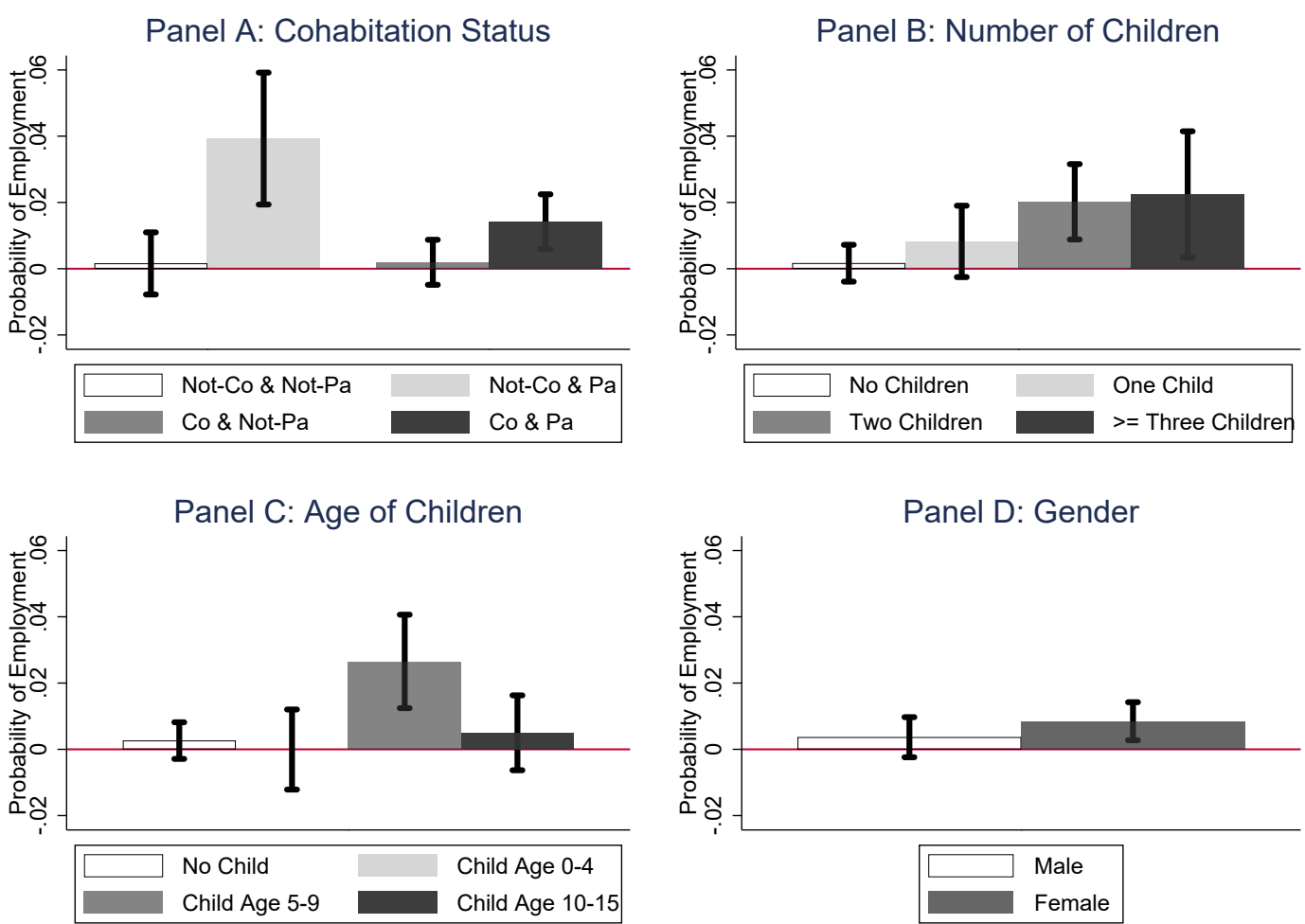

The figure examines whether the impact of television on employment probabilities is heterogeneous in cohabitation status and the number and age of children. It also explores the impact of television on gender equality in the labour market. 
Figure 8: Type of Employment
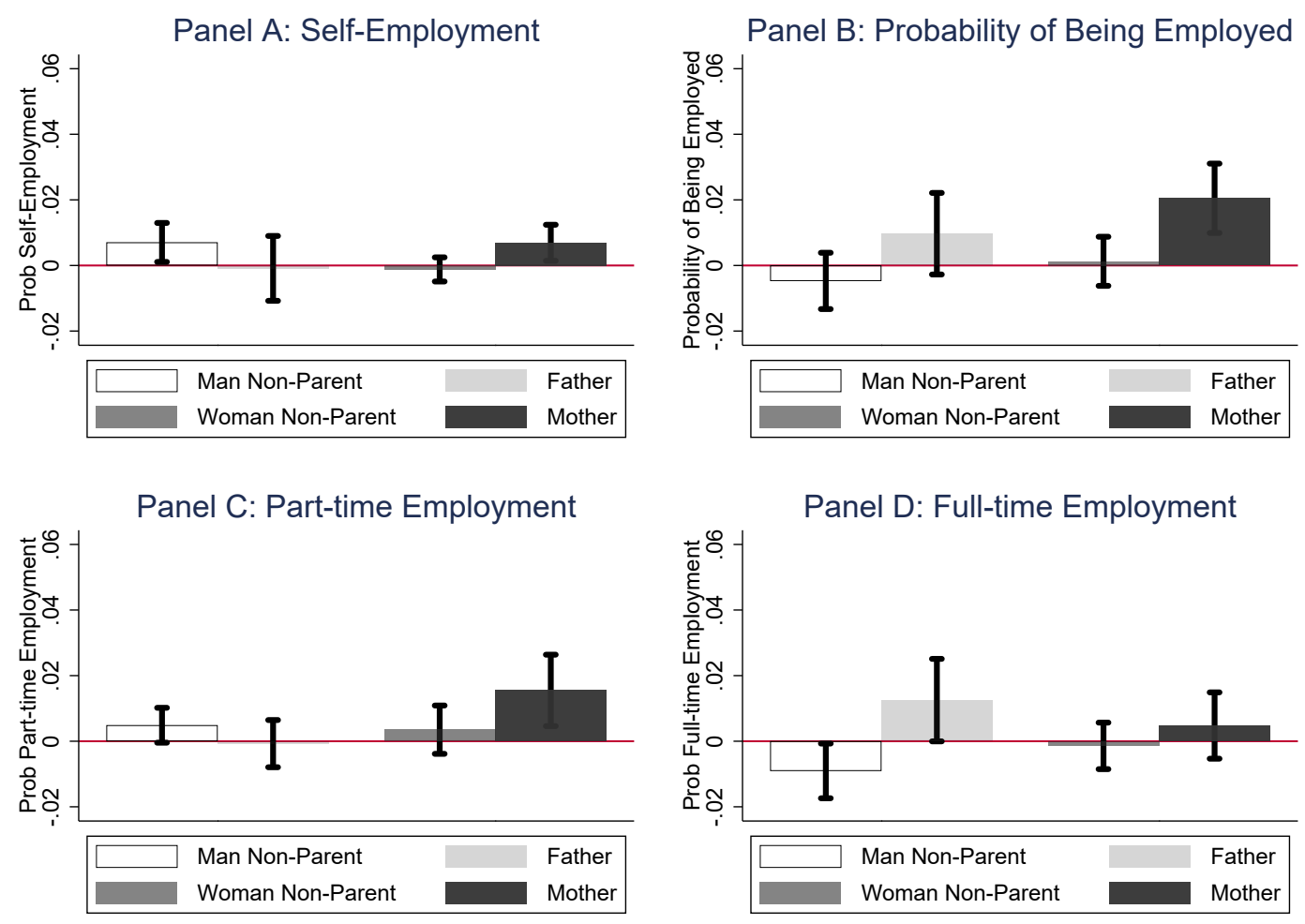

Panels A-D examine the impact of television on the following labour outcomes: (i) self-employment, (ii) the probability of being employed, (iii) part-time employment, and (iv) full-time employment, respectively.

Figure 9: Housework
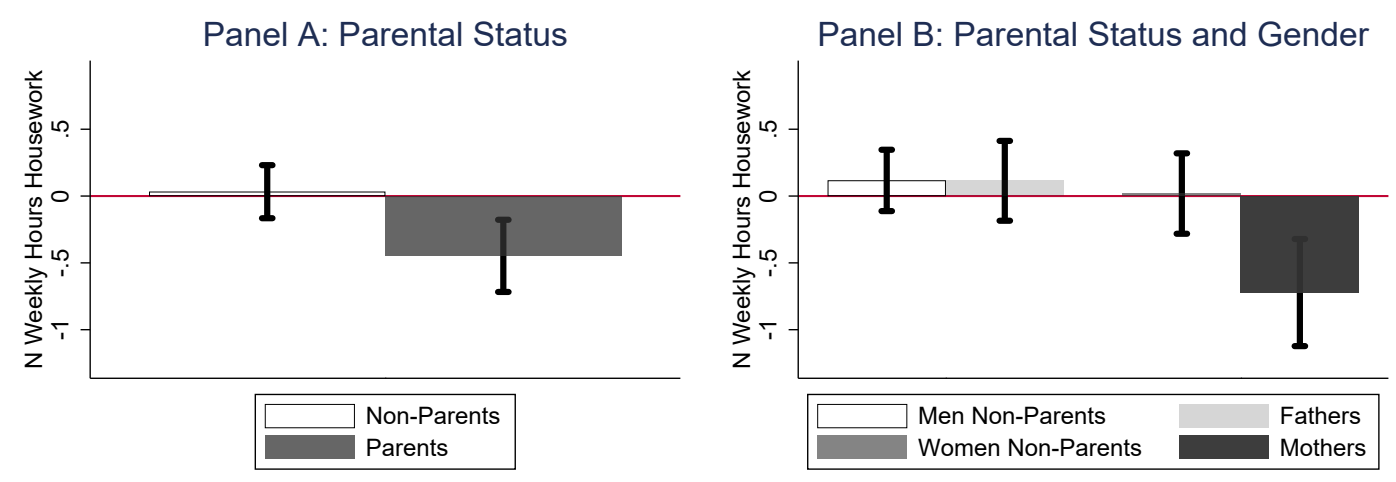

The figure examines whether the impact of television on the amount of housework is heterogeneous in gender and parental status. 


\section{Tables}

Table 1: Descriptive Statistics

\begin{tabular}{|c|c|c|c|c|c|}
\hline & \multicolumn{4}{|c|}{ Digital Television Introduction Year } \\
\hline & & 2009 & 2010 & 2011 & 2012 \\
\hline \multirow[t]{2}{*}{ Gender } & 0.55 & 0.56 & 0.54 & 0.55 & 0.55 \\
\hline & $(0.50)$ & $(0.50)$ & $(0.50)$ & $(0.50)$ & $(0.50)$ \\
\hline \multirow[t]{2}{*}{ Age } & 48.37 & 49.26 & 49.57 & 48.57 & 47.66 \\
\hline & $(17.83)$ & $(18.04)$ & $(17.71)$ & $(17.82)$ & $(17.80)$ \\
\hline \multirow[t]{2}{*}{ Race } & 0.19 & 0.10 & 0.07 & 0.16 & 0.27 \\
\hline & $(0.39)$ & $(0.30)$ & $(0.25)$ & $(0.37)$ & $(0.45)$ \\
\hline \multirow[t]{2}{*}{ Single } & 0.20 & 0.18 & 0.17 & 0.19 & 0.23 \\
\hline & $(0.40)$ & $(0.38)$ & $(0.37)$ & $(0.39)$ & $(0.42)$ \\
\hline \multirow[t]{2}{*}{ Married/Civil Partner } & 0.55 & 0.55 & 0.55 & 0.55 & 0.54 \\
\hline & $(0.50)$ & $(0.50)$ & $(0.50)$ & $(0.50)$ & $(0.50)$ \\
\hline \multirow{2}{*}{ Separated/Divorced } & 0.08 & 0.10 & 0.09 & 0.08 & 0.08 \\
\hline & $(0.28)$ & $(0.30)$ & $(0.28)$ & $(0.28)$ & $(0.27)$ \\
\hline \multirow[t]{2}{*}{ Widowed } & 0.06 & 0.07 & 0.07 & 0.06 & 0.06 \\
\hline & $(0.24)$ & $(0.26)$ & $(0.25)$ & $(0.23)$ & $(0.24)$ \\
\hline \multirow[t]{2}{*}{ Living as a Couple } & 0.10 & 0.11 & 0.13 & 0.12 & 0.08 \\
\hline & $(0.30)$ & $(0.31)$ & $(0.33)$ & $(0.32)$ & $(0.27)$ \\
\hline \multirow[t]{2}{*}{ Household Size } & 2.91 & 2.71 & 2.64 & 2.87 & 3.04 \\
\hline & $(1.50)$ & $(1.36)$ & $(1.28)$ & $(1.46)$ & $(1.59)$ \\
\hline \multirow[t]{2}{*}{ Highly Qualified } & 0.35 & 0.35 & 0.38 & 0.33 & 0.37 \\
\hline & $(0.48)$ & $(0.48)$ & $(0.49)$ & $(0.47)$ & $(0.48)$ \\
\hline \multirow[t]{2}{*}{ Labour Market Participation } & 0.61 & 0.60 & 0.63 & 0.62 & 0.61 \\
\hline & $(0.49)$ & $(0.49)$ & $(0.48)$ & $(0.49)$ & $(0.49)$ \\
\hline \multirow[t]{2}{*}{ Has a Job } & 0.56 & 0.55 & 0.59 & 0.56 & 0.56 \\
\hline & $(0.50)$ & $(0.50)$ & $(0.49)$ & $(0.50)$ & $(0.50)$ \\
\hline \multirow[t]{2}{*}{ Unemployed } & 0.05 & 0.05 & 0.04 & 0.05 & 0.06 \\
\hline & $(0.22)$ & $(0.21)$ & $(0.19)$ & $(0.22)$ & $(0.23)$ \\
\hline \multirow[t]{2}{*}{ Permanent Employee } & 0.92 & 0.92 & 0.92 & 0.93 & 0.91 \\
\hline & $(0.27)$ & $(0.27)$ & $(0.27)$ & $(0.26)$ & $(0.29)$ \\
\hline \multirow[t]{2}{*}{ Full-Time Employee } & 0.72 & 0.73 & 0.72 & 0.72 & 0.73 \\
\hline & $(0.45)$ & $(0.45)$ & $(0.45)$ & $(0.45)$ & $(0.45)$ \\
\hline Observations & 184,092 & 15,210 & 13,569 & 87,866 & 67,447 \\
\hline
\end{tabular}

The table presents the averages of several labour outcomes and sociodemographic characteristics, together with their standard deviations in parentheses. Column 1 presents unweighted summary statistics of the sample. Columns $2-5$ split the sample according to the year when individuals received access to digital signal. 
Table 2: Baseline Results

\begin{tabular}{lccc}
\hline & Dep Var: & Prob Employment \\
\hline DT & $0.011^{* * *}$ & $0.013^{* * *}$ & $0.006^{* *}$ \\
& $(0.002)$ & $(0.003)$ & $(0.002)$ \\
Individual Covariates & No & No & Yes \\
LSOA Dummies & No & Yes & Yes \\
Year Dummies & No & Yes & Yes \\
\hline Observations & 185,338 & 184,092 & 178,724 \\
\hline
\end{tabular}

$* \mathrm{p}<0.10,{ }^{* *} \mathrm{p}<0.05,{ }^{* * *} \mathrm{p}<0.01$

Standard errors in parentheses. The individual covariates that I use in column 3 are: gender, a third-order polynomial in age, ethnicity, level of qualification, marital status, and the number of household members. I cluster standard errors at the LSOA level.

Table 3: Local Labour Markets

\begin{tabular}{lccc}
\hline & Dep Var: & Prob of Employment \\
\hline DT & $0.013^{* * *}$ & $0.010^{* * *}$ & $0.011^{* *}$ \\
& $(0.003)$ & $(0.004)$ & $(0.004)$ \\
LSOA Dummies & Yes & Yes & Yes \\
Year Dummies & Yes & Yes & Yes \\
Country*Year Dummies & Yes & No & No \\
GOR*Year Dummies & No & Yes & No \\
LA*Year Dummies & No & No & Yes \\
\hline Observations & 184,092 & 184,092 & 184,074 \\
\hline
\end{tabular}

${ }^{*} \mathrm{p}<0.10,{ }^{* *} \mathrm{p}<0.05, * * * \mathrm{p}<0.01$

Standard errors in parentheses. I cluster standard errors at the LSOA level. GOR is the abbreviation for Government Office Region. LA is the abbreviation for Local Authority. 
Table 4: Further Robustness Tests

\begin{tabular}{lcccc}
\hline & \multicolumn{4}{c}{ Dep Variable: Probability of Employment } \\
\hline & Never & No TV & Transmitter & $2009-2013$ \\
Moved & \multicolumn{4}{c}{ Dummies } \\
\hline DT & $0.008^{* * *}$ & 0.018 & $0.006^{* *}$ & $0.004^{*}$ \\
& $(0.003)$ & $(0.030)$ & $(0.002)$ & $(0.003)$ \\
Individual Covariates & Yes & Yes & Yes & Yes \\
LSOA Dummies & Yes & Yes & Yes & Yes \\
Year Dummies & Yes & Yes & Yes & Yes \\
Transmitter Dummies & No & No & Yes & No \\
\hline Observations & 140,445 & 1,852 & 178,724 & 150,401 \\
\hline
\end{tabular}

$* \mathrm{p}<0.10,{ }^{* *} \mathrm{p}<0.05,{ }^{* * *} \mathrm{p}<0.01$

Standard errors in parentheses. I control for the following individual covariates: gender, a third-order polynomial in age, ethnicity, level of qualification, marital status, and the number of household members. I cluster standard errors at the LSOA level.

Table 5: Family Difficulties and Gender Views

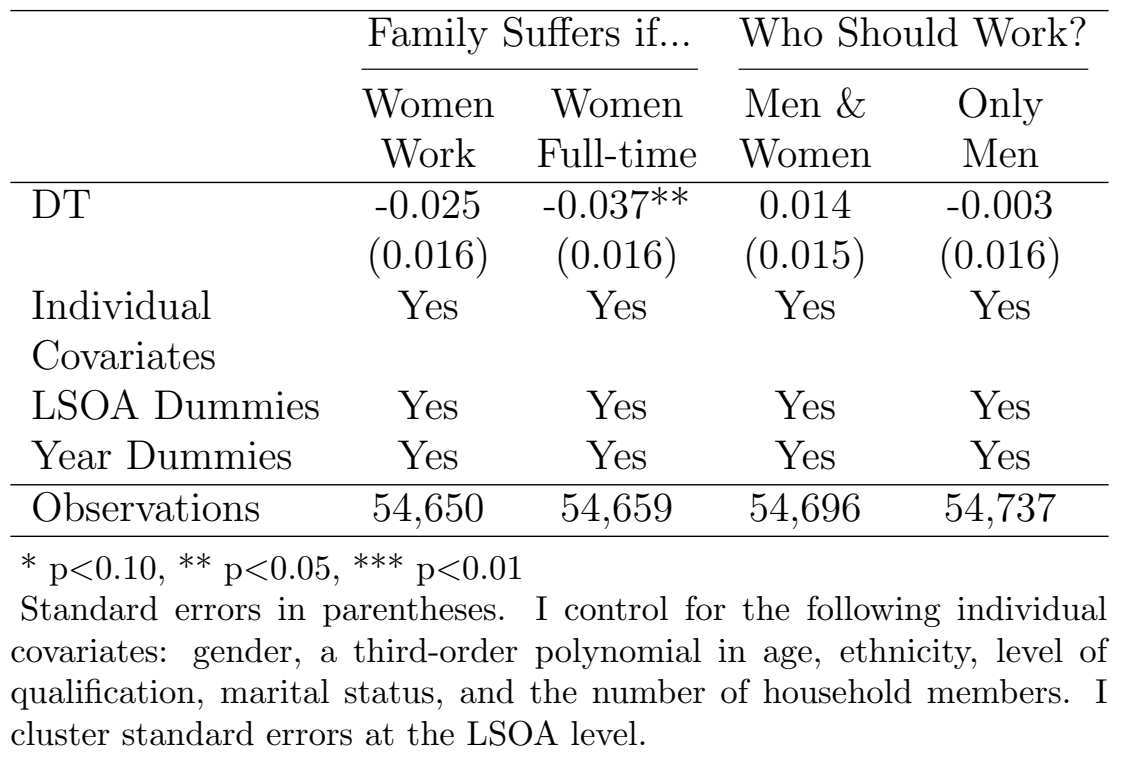




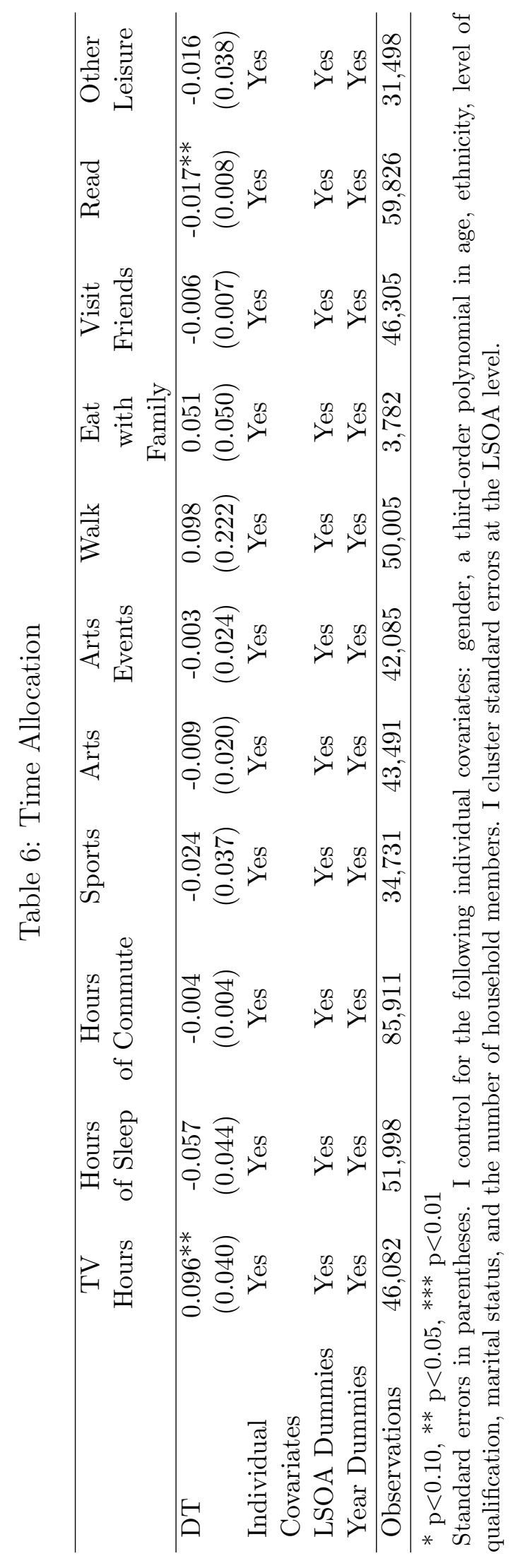




\section{A Appendix}

\section{A.1 TV Viewing Share by Genre}

Figure A.1 presents the proportion of TV watching time that viewers dedicate, on average, to each genre. I classify TV content into thirteen genres: entertainment, movies, sports, relaxation, humour, drama, soap operas, cultural programmes, contemporary matters, newscasts, educational content, cartoons, and other. As shown, TV content does not change much during the period of 2007-2014.

Figure A.1: TV Viewing Share by Genre

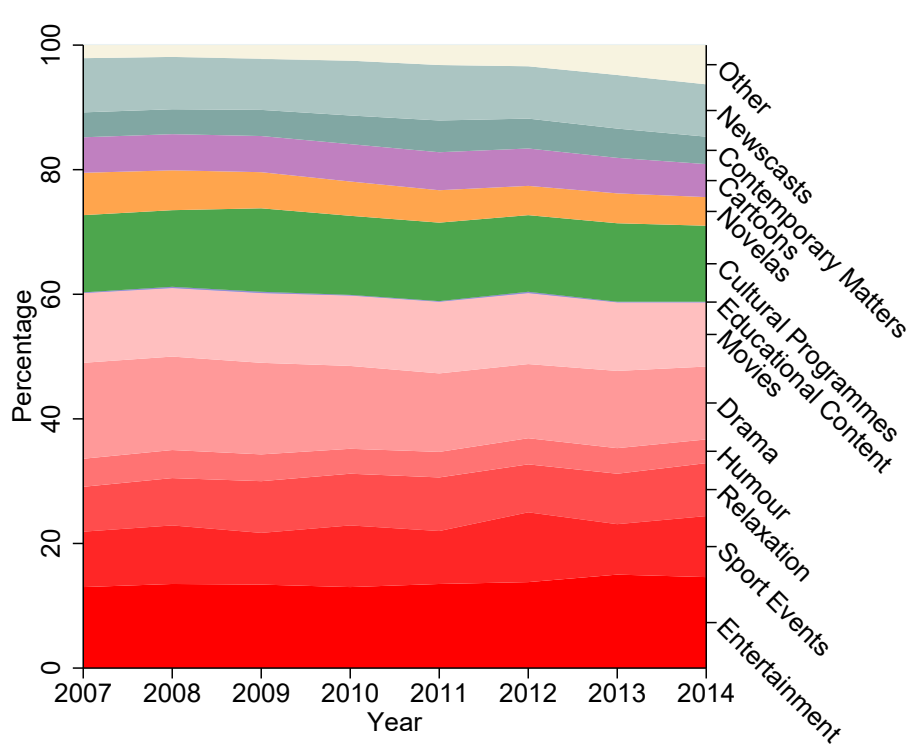

The figure shows the proportion of television watching time that viewers dedicate on average to each genre. I classify TV content into the following genres: entertainment, movies, sports, relaxation, humour, drama, soap operas, cultural programmes, contemporary matters, newscasts, educational content, cartoons, and other.

\section{A.2 Local Services}

It is important to explore whether the impact of television on employment probabilities varies according to the amount of public services provided in the local area. Table A.1 estimates the baseline specification and splits the sample according to the quality of (i) primary schools, (ii) leisure activities, and (iii) public transport in the 
local area. In particular, columns 1-2 study the effect of television on employment probabilities when the quality of primary schools that individuals report having in their local area is above/below the average of the sample, respectively. Columns 3-4 study heterogeneity in the quality of the leisure activities available in the local area. Columns 5-6 study heterogeneity in the quality of public transport. I only find that the estimates of the digital transition are higher when the quality of public transport is worse.

Table A.1: Heterogeneity in Local Services

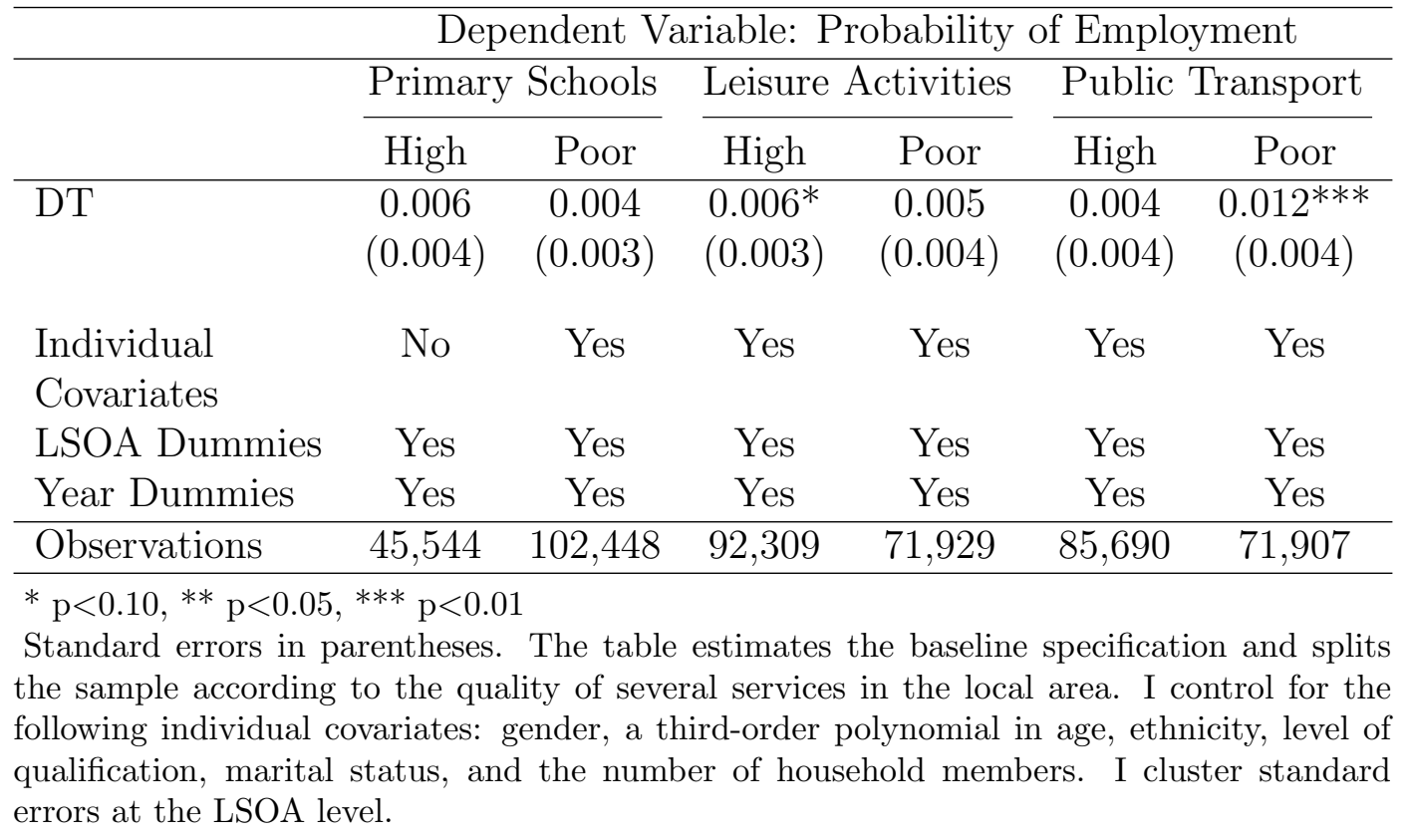

\section{A.3 Level of Qualification}

This subsection studies whether the impact of the digital transition on employment probabilities varies by parental status and level of qualification. To do so, I estimate a specification similar to the baseline model but that controls for parental status and its interaction with the switchover variable, separately by level of qualification. I classify individuals as high-qualified (if their highest qualification is a university degree or other higher degree) and low-qualified (if their highest qualification is Alevels, GCSE, other qualification, or no qualification). Figure A.2 shows that the 
digital transition increases more employment probabilities for high-qualified parents than for low-qualified ones, albeit these estimates are not statistically different.

Figure A.2: Parental Status and Level of Qualification

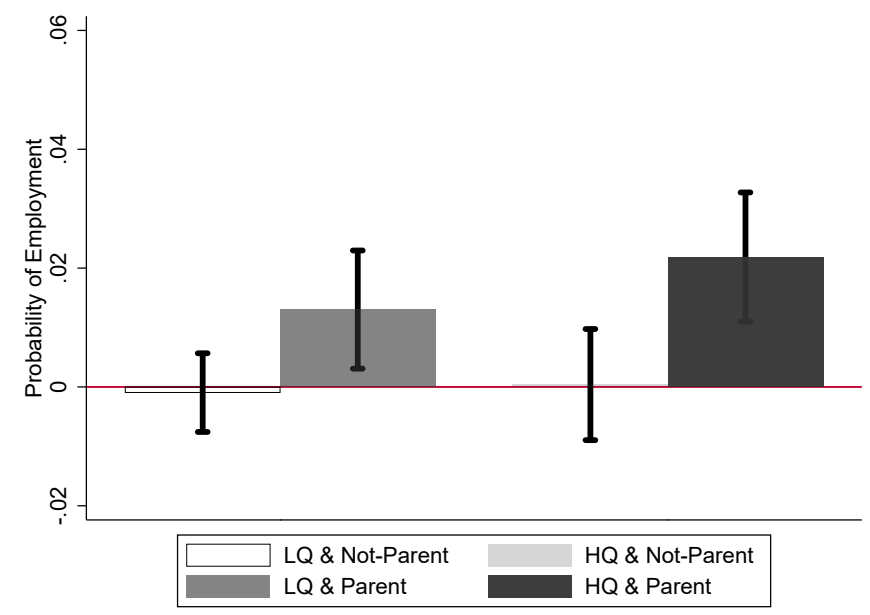

The figure examines whether the impact of television on employment probabilities is heterogeneous in parental status and level of qualification.

\section{A.4 Number of Hours Worked}

This paper studies whether the digital transition has an impact on employment probabilities. It is also relevant to examine whether television changes the intensive margin of the labour supply. To do so, I estimate a specification similar to the baseline one but that controls for parental status and its interaction with the digital transition variable. I use the number of hours worked per week as dependent variable. As shown in Figure A.3, the digital transition increases working hours for mothers and fathers but has no impact for non-parents. 
Figure A.3: Number of Hours Worked

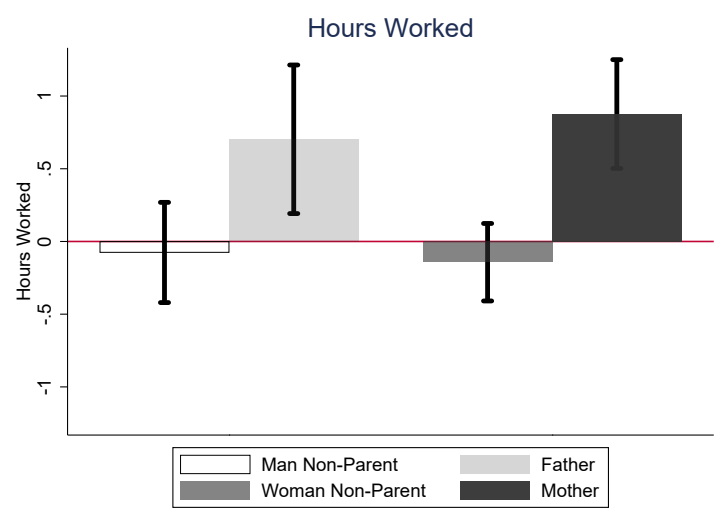

The figure examines whether the impact of television on working hours is heterogeneous in parental status and gender.

\section{A.5 Work from Home}

This subsection studies whether the digital transition has an impact on the probability of adults working from home, and examines heterogeneity in the previous effect by parental status and gender. I estimate an equation similar to the baseline model but that controls for parental status and its interaction with the switchover variable, separately by gender. Figure A.4 shows that the digital transition has no impact on the probability of individuals working from home, independently of their parental status and gender. 
Figure A.4: Work from Home

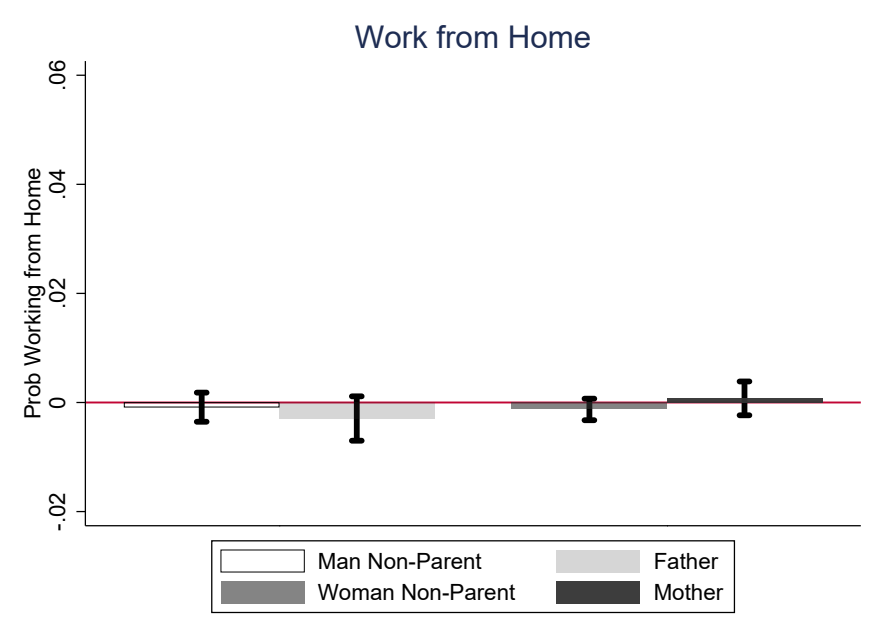

The figure examines the impact of television on the probability of working from home, and investigates heterogeneity in the previous effect by parental status and gender. 
